DOI: https://doi.org/10.30837/MMP.2021.091

\title{
RESEARCH OF THE INFLUENCE OF THE PERFORMANCE TERM ON THE COST OF THE INNOVATION AND INVESTMENT PROJECT
}

\author{
Konashchuk V.
}

The methodological foundations of microeconomic analysis of the project form of innovative-investment activity are developed in the article. The concept of acquiring of time the properties of an economic resource in the process of implementing an innovation and investment project is proposed. The concept of production function of project innovation-investment activity introduced by the author has been clarified and improved. It has been established that the choice of the term for the implementation of the innovation and investment project is actually the chronological placement of the contracting resource required to carry out work according to the corresponding organizational and technological scheme. This choice is influenced by subjective and objective factors. The latter are the main criterion for the above selection. This is a criterion for minimizing the economic value of the project, which should be understood as the future value of the costs of its implementation, including implicit costs. The structure of economic value of the project is analyzed in detail, the procedure of formation and interdependence of its components is defined. As a result, it is established that the economic value of the project is formed by two resources - the contract resource and time, therefore magnitude economic value depends primarily on the parameters of the value of these resources - specific value added and interest rate. Optimization of term of realization of project on the criterion of minimization of him economic cost allows choose the rational for these economic terms method of realization of project. He envisages also the rational placing of the invested money in time. It can improve the indexes of estimation of efficiency of long-term innovative-investment projects that will add arguments to the supporters of expediency of their realization.

Keywords: innovation-investment activity, project, contracting and time resources, production function of project activity, economic cost of the project.

\section{INTRODUCTION}

Universally recognized, that the state and dynamics of socio-economic development in the modern world in large part are determined by a scale and intensity of innovative-investment activity of economic subjects [1, p. 14, 2]. 
In the economically developed (or rich) countries innovative-investment activity usually is higher, and vice versa, in countries poor (or those that develop) this activity is subzero comparatively $[3,4$, p. 18]. One of important reasons of such state there is a lack of accessible at price capital in poor countries [5, p. 86]. Why this reason is important? Innovative-investment activity comes true mainly in form corresponding projects. A question about expedience of realization of that or other project decides on the basis of comparison of charges on realization of project and profits that generated them. It is good worked out within the framework of financial management and project analysis methodology [6, 7]. As in poor countries the cost of capital is high, rate of discount accordingly too high. For long-term capital investments, for example, in industrial assets, the high rate of discount will result in worsening of indexes of estimation of efficiency of project. The near to the zero of NPV will not add to enthusiasm to the supporters of expediency of investments in innovative development of productive base, an effect from that will be remote in time. But also in rich countries can take place analogical problems. Especially it touches the projects of investing in an ecological capital, social development, infrastructure and others like that. Only part of effect from realization of many such projects generates a money stream. That is, such crypto-profitable projects are characterized by a latent from the point of view of financial materialization public utility, and theirs NPV too subzero is an. It complicates or and does impossible a decision about expedience of their realization.

However, some reservations about the reliability of NPV and other indicators indicate that a more rigorous approach is needed to determine them. After all, for the calculation of income cash flow is usually used probabilistic data. They reflect future developments that will be influenced by many variables. Similarly probable are the data for calculating the cash flow of costs that will also be made in the future (planned investments), although the methodology developed in the framework of project management allows to minimize this deficiency in the project implementation process $[8,9]$. But this is not the only reason. The amount of cash flow of a long-term innovation investment project depends to a certain extent 
on the manner and timing of implementation of the project. The application of a microeconomic analysis methodology to study the economic nature of project activity allows us to better understand this dependency and how it affects NPV and other performance indicators of long-term complex investment projects.

\section{INTERDEPENDENCE OF PARAMETERS OF IMPLEMENTATION OF INNOVATION AND INVESTMENT PROJECT}

The project activity combines two integrated economic resources - contractor (material and human resources of the contractor in combination with the ability to perform contract work) and time (combination of time as a physical resource and the ability to increase capital over time). This is done by chronologically allocating the required amount of contract resources in accordance with the organizational and technological scheme adopted for the project. The result of project activities is the creation of new value as an object of the project, in fact, achieving the goal of the project implementation process. Given this, we can define a general view of the twofactor production function of the project:

$$
S=F(R, T),
$$

where $S$ is a quantitative characteristic of the project (or the amount of contract work on the project); $R$ is the amount of contracted resource involved in the project implementation; $T$ is possible duration of project implementation (quantitative description of time required for project implementation) [10, p. 768].

In fig. 1 shows the project isoquant - a graphical view of the production function of the project or project activity (production, which is a set of services and works on the project implementation) in the coordinates "contracting resources $R$ - time resource (possible duration of project implementation) $T^{\prime \prime}$ [11, p. 219]. 


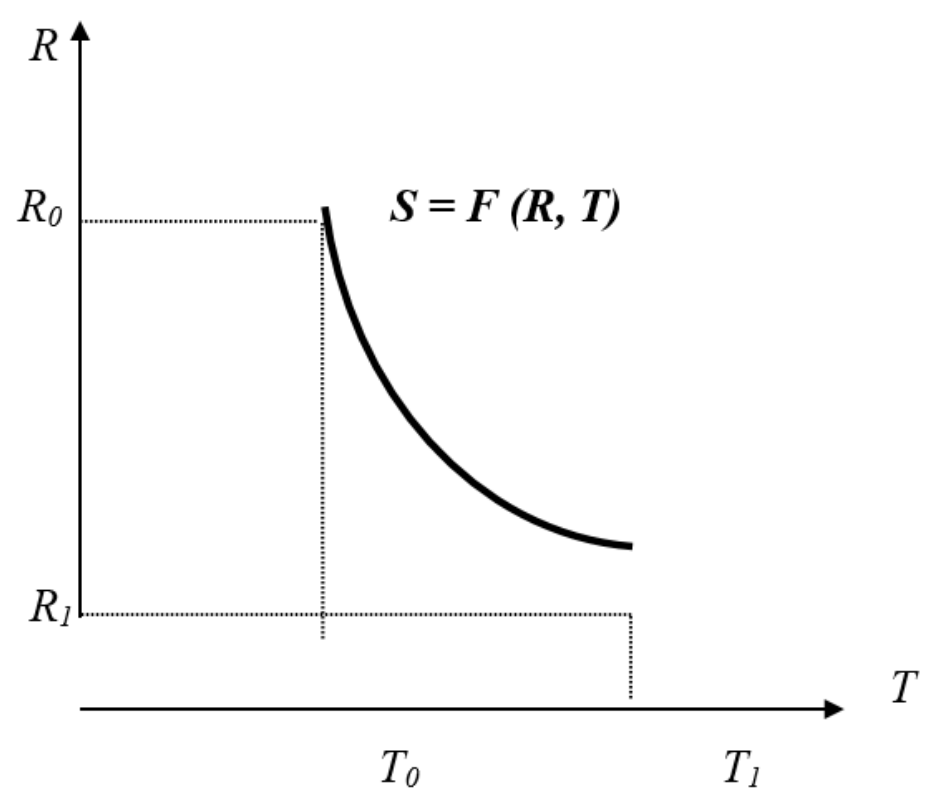

Fig. 1. Isoquant project [5]

It is similar to the curve of the production function of traditional production. The logical explanation for this kind of project isoquant is the following. Each project work requires a certain amount of time and a certain amount of contracting resources. You can speed up your work by increasing the number of performers, and vice versa. The interconnectedness of the work can affect this pattern (for example, a significant increase in the amount of contracting resources can only slightly reduce the duration of the project), but it cannot change it dramatically.

The production function of the project describes a number of organizational and technological schemes of project work, each of which is designed to mobilize time and contract resources in an amount sufficient to implement the project (performance of certain volumes of contract work). In other words, each isoquant point characterizes a certain quantitative combination of time and contract resources. For each project there is a certain set (map) of isoquants, but only one of them (closest to the origin) represents the efficient use of resources for the best organization and technology of work for each organizational and technological scheme of their implementation (or for each combination of resources). It is a set of technically effective organizational and technological schemes for the technological level of the corresponding contract activity achieved in the world practice. 
The production function of the project has the following properties.

1. Mutual substitution of factors of production - contractual and time resources. This means that the contracting resource can be replaced by time and vice versa, thus changing the volume of the contracting resource flow (that is, its amount involved in each individual work period) in certain ratios (and to a certain extent). These ratios are determined by the second property.

2. Complementarity of factors of production. The presence of both of the above properties (mutual substitution and complementarity) is explained by the fact that contracting and time resources, as noted, are combined by allocating the required volume of the contracting resource in time depending on the given duration of project implementation and in accordance with the adopted organizational and technological scheme.

3. All points of the isoquant of a particular project are hypothetical except one (it is determined only after the project implementation process is completed).

4. A cost-effective organizational and technological scheme for the execution of the contract work on the project will not necessarily be technically efficient (it will not necessarily belong to the isoquant closest to the origin). For example, in the case of low labor costs, the cost of acquiring more technologically backward contracting resources may be lower than acquiring fewer advanced ones [12, p. 76].

To overcome the impact of the fourth feature on the validity of further research, we introduce the concept of local technical effectiveness of organizational and technological schemes of project implementation, which should be understood as the best opportunity of potential contractors in terms of organization and technology to perform works on the project. Since the isoquant of technically efficient organizational and technological schemes may not be available for the implementation of a specific project, we will consider local technically effective organizational and technological schemes as the closest to the beginning of the isoquant coordinates. Due to the fact that the technological level of contracting activity in a certain sense is a consequence of the dynamics of the price situation in the resource markets, a cost-effective organizational and technological scheme for 
the implementation of a particular project will always be locally technically effective scheme.

Suppose that in fig. 1 shows the closest to the origin coordinates of an isoquant of a project. Then $T_{0}$ and $T_{1}$ are the limit values the duration of the project: for any number of $\mathrm{R}>\mathrm{R}_{0}$ it is not possible to execute the project during $\mathrm{T}<\mathrm{T}_{0}$. At the same time, involving the minimum amount of contractual resource $\mathrm{R}_{1}$, taking into account the organizational and technological continuity of the project implementation process, the project can be implemented no longer than $\mathrm{T}_{1}$. Further minimization of the amount of contracted resources involved makes it impossible for the organizational and technological continuity of the project implementation process. Thus, the rational owner of the project will choose the term of its implementation in the range from $T_{0}$ to $T_{1}$.

The criteria for choosing the project implementation deadline can be both objective and subjective factors. But in our opinion, the criterion of minimizing the economic value of the project should be a priority.

\section{FORMATION OF THE COST OF AN INNOVATION AND INVESTMENT PROJECT}

The economic value of the project will mean the future value of the aggregate of all costs of the project owner for its implementation, including implicit ones. All of these costs are related to contracting works, because in a physical dimension, a project is a set of interrelated works that are performed in a certain sequence. So the project implementation process is the process of contractors performing works whose scope, regardless of the technology used and the duration of the project implementation, is set. In this case, the actual amount of contracting work may differ from the planned (given) due to the probabilistic nature of future planning of processes and other factors, but due to the procedures and methods of planning, risk insurance, etc., worked out within the framework of project management methodology, this does not fundamentally affect the nature of the scope of work on the project. Therefore, if the planned volume of contracting works $S_{p l}=$ const, then 
the total amount of contracting resource (reserve of contracting resource) required for the project implementation is a constant value. However, the amount of contracted resource involved in each individual time period (the volume of contracted resource flow) depends ultimately on the duration of the project [13, p. 854]. Then, in the general form, the economic value of the project (the economic value of the contracted work $C$ ) can be determined by the following formula:

$$
C=\sum_{n=1}^{N} Q_{n} \sum_{t=1}^{T} q_{n t}(1+r)^{t}+\sum_{n=1}^{N} \sum_{t=1}^{T} m_{n t}(1+r)^{t},
$$

where $w$ is the economic cost of the project; $Q_{n}$ is the unit price of the nth contracting resource, which is the value added, created by the unit of the nth contracting resource (specific value added); $N$ is number of different contracting resources involved in this project; $T$ is term of project implementation; $q_{n t}$ is a quantitative characteristic of the executive (labor) component of the nth contracting resource involved in the $t$ period; $m_{n t}$ is the cost characteristic of the supply (material) component of the nth contracting resource involved in the t period; $r$ is the interest rate.

As can be seen from (2), the contracting (mainly labor) component of contracting resources plays an important role in shaping the economic value of the project. This is due to the characteristic feature of project-oriented production. Unlike conventional production, in which the share of the labor component is constantly reduced through capitalization due to mechanization, automation and robotization of production processes, the labor component in project-oriented production will always be key, it is much more difficult to capitalize due to the specifics of contracting work (in particular, through high proportion of organizational, managerial, creative and other components of heuristic character).

Also, the formation of the economic value of the project is significantly influenced by the chronological location of contract work. This is primarily due to the change in the value of money over time. Assuming that we have the best 
conditions to finance the project - full pre-payment for contracting, the formula for determining the economic cost of implementing the project is somewhat simplified:

$$
C=\sum_{n=1}^{N}\left(Q_{n} R_{n}+M_{n}\right) \cdot(1+r)^{T},
$$

where $C$ is the economic cost of the project; $Q_{n}$ is the unit price of the nth contracting resource, which is the value added, created by the unit of the nth contracting resource (specific value added); $R_{n}$ is the total amount of labor component of the nth contracting resource; $M_{n}$ is the total cost of the material component of the nth labor resource; $N$ is number of different contracting resources involved in this project; $T$ is term of project implementation; $r$ is the interest rate.

It should be noted that the cost of the temporary resource will become clear if the project owner borrows funds to finance the project. If you use your own funds, the cost of the temporary resource will remain implicit.

To simplify the analysis of project activity, let's consider a hypothetical project that is implemented using the same type of contracting resource for period $\mathrm{T}$ on the condition of full prepayment of contracting works. If you use the value of the given interest rate, given the condition of prepayment of works, we will have:

$$
C=(Q R+M) r^{\prime}
$$

where $C$ is the economic cost of the project; $R$ is the total amount of labor component of the same contractual resource; $Q$ is specific value added of the same contractual resource; $M$ is the total cost of the material component of the same contractual resource; $r^{\prime}$ is converted interest rate, $r^{\prime}=(1+r)^{T}$.

By the way, this simplification is not far from reality, since the components of the economic value of any project involving different types of contracting resources can always be reduced to one type of resource, namely:

- the labor component $-R=\sum_{n=1}^{N} R_{n}$;

- the specific value added $-Q=\sum_{n=1}^{N} Q_{n} R_{n} / \sum_{n=1}^{N} R_{n}$;

- the material component $-M=\sum_{n=1}^{N} M_{n}$. 
In formula (4) $M=$ const and $R=$ const because $S_{p l}=$ const. The value of $Q$ is formed in the contract market and, subject to the price policy adjustment of the project owner, is accepted for the project, provided that its implementation period allows a rational way to use the contract resource. If necessary, forcing the works or extending them, $Q$ may deviate significantly from the market value. In the general case, the market value of $Q$ is the basis for determining the contractual value of $Q$, taking into account the impact of the duration of contracting:

$$
Q=f(T) .
$$

This impact, in turn, is determined on the basis of the ratio of supply and demand of contracting resources within a specific project for each possible term of its implementation. But the mechanism of formation of the above demand for contracting resource should be the subject of separate research. Then, given (4) and (5), we have:

$$
C=F(T ; r) \text {. }
$$

Therefore, all things being equal, the economic value of the project depends on the duration of the project and the interest rate. That is, changing the amount of time resource (spent on the project implementation) determines some of the volatility of the economic cost of the project. But on what basis does the project owner decide to use a time resource? What objective factor is most influential in making this decision? Obviously, it is the interest rate that determines the value of the time resource.

It should be noted that the value of the material component of the contracting resource $M$ is deterministic, since it is formed on the basis of prices drawn up in the relevant adjacent markets (for example, markets for laboratory tests and tests, equipment, construction materials etc.), and its impact on time can be to some extent neutralized by logistics. Usually, the project owner makes the most important decisions on the price and timing of the project in the course of the agreements with the contractors, ie operating in the contract markets. Then the decisive role in shaping the economic value of the project will have its variable component - added value: 


$$
C_{D}=Q R(1+r)^{T},
$$

where $C_{D}$ is the added value of the economic value of the project; $Q$ is specific value added of the same contractual resource; $R$ is the total amount of labor component of the same contractual resource; $T$ is project implementation term; $r$ is the interest rate.

The decision to use the time resource rationally is to decide whether it is appropriate to replace it with a contractual resource (or vice versa). Suppose that the project owner has the ability to attract an additional amount of the contracting resource $\Delta R$ at the same price $Q$, and thereby reduce the project implementation time by of $\Delta T$. Then the value added in the economic value of the project will be:

$$
C_{D}^{\prime}=Q R(1+r)^{(T-\Delta T)},
$$

where $C_{D}^{\prime}$ is the value added after shortening the project implementation period; $Q$ is the price (unit value added) of the same contractual resource that has not changed; $R$ is the total amount of labor component of the same contractual resource; $T$ is project implementation term; $\Delta T$ is the magnitude of the project implementation deadline; $r$ is the interest rate.

As can be seen from (8), a higher interest rate will lead to a more significant effect (for value added) of replacing the time resource with a contractor, regardless of $\Delta R$. Although $\Delta R$ and $\Delta T$ are interrelated, there is only $R$ in the formula, which is constant (using a larger of the contractor's workforce $R+\Delta R$ over a shorter duration of $T-\Delta T$ will not change the contractor's $R$ required to complete the project). Thus, the decision on the appropriateness of replacing the time resource with the contract resource depends largely on the interest rate. You should also pay attention to the possibility of attracting additional contractual resources in this case at a constant price $Q$. Obviously, such opportunities can occur in real economic situations. But in the general case, when attracting more contracting resources to perform the project work in order to shorten the period of its implementation, the cost of contracting resources may increase, as noted above (5). This is explained, in particular, by the fact that the specific value added is, firstly, the price of the contract resource (demand factor for it in the project), and secondly, characterizes the contractor's costs for the 
work, i.e. the supply factor of the contract resource in the project. In the second case, the dependence (5) is a priori, and through the mechanism of interaction of supply and demand of the contract resource in the project, the same type of dependence is formed in the first case. All this confirms the dependence (6).

To sum up, it should be noted that the formalization of the project, like any systemic economic interaction, is rather conditional. However, it allows us to better understand the rational ways of implementing projects and the interdependence of the parameters of their implementation. Reinforcing the considerations set out in this work with appropriate techniques and software will enable you to put this understanding into practice.

\section{CONCLUSIONS}

1. Project implementation time is a more important parameter. It not only determines the physical time limits of the project, but also in some way affects the cost of its implementation.

2. Optimization of the project implementation period according to the criterion of minimizing its economic value allows you to choose the way of realization of the project rational for these economic conditions. It also provides for a rational allocation of invested capital over time. This can improve the performance evaluation of long-term innovation-investment projects (especially with a high level of innovation) and crypto-profitable projects, which will give arguments to supporters of the feasibility of their implementation.

3. The interest rate has a significant impact on the choice of project implementation parameters. Therefore, this study is more relevant for developing countries. In these cases, central bank interest rates are often several times or an order of magnitude higher than central bank interest rates in rich countries. This leads to high the cost of capital and has a very negative impact on the investment process. In such circumstances, it is difficult to ensure high efficiency and effectiveness of the project, so governments and central banks must ensure the availability of investment capital. 
4. This study has the prospect of further development in theoretical and practical aspects. The production function of the project and new indicators for determining the value can form the basis of a chronological methodology for managing innovation and investment projects and innovative development of enterprises.

\section{REFERENCES}

1. Problems of managing innovative development of enterprises in a transitive economy. Monograph / edited by S. M. Illiashenko. - Sumy: Universytetska knyha, 2005. - 582 p.

2. Kholod, B., Tkachenko, V, Tian, R., Chimshit, S., Shchukin, A. Fundamentals of competitive advantage and innovative development. - Dnipro: Monolit, 2008. - 474 p.

3. Investment-innovation activity: theory, practice, experience. Monohraph / edited by M. P. Denysenko, L. I. Mykhailova. - Sumy: Universytetska knyha, 2008. - 1050 p.

4. Organization and management of innovation activities. Monohraph / edited by P. H. Pererva, S. M. Mekhovych, M. I. Pohorielov. - Kh. : NTU KhPI, 2008. - 1025 p.

5. Kovalenko O.V., Konashchuk V.L., Kromska L.A. Innovation management - ways to improve. - Zaporiggja: RVV ZDIA, 2014. - 143 p.

6. Brigham, E. Fundamentals of Financial Management, 7th ed. - Kyjiv: Molod, 1997. - 1002 p.

7. Blanc, I. Investment management. - Kyjiv: ITEM, 1995. - 304 p.

8. Reschke, H., Schelle, H. World of project management. - Moskva: Alans, 1994. - 304 p.

9. Tian R. B., Kholod B. I., Tkachenko V. A. Project management. Textbook. - D.: DUEP, 2002. -224 p.

10. Konashchuk V. L. Microeconomic analysis of the investment project implementation process // Economics: problems of theory and practice. Collection of scientific works. V. 212. III - D.: DNU. - 2006. - P. 767 - 773

11. Konashchuk V. L. Theoretical aspects of evaluating the effectiveness of innovative activities of construction companies // Economic space. Vol 38 - D.: PSABA. - 2010. - P. 217 - 224

12. Konashchuk V. Methodological aspects of the analysis of the project form of innovationinvestment activity // Economic bulletin Ukrainian State University of Chemical Technology. - 2019. - №2. - P. 73-80

13. Konashchuk V. L. Theoretical aspects of determining the parameters of the investment project // Economics: problems of theory and practice. Collection of scientific works. V. 232. IV- D.: DNU. - 2006. - P. 852 - 858. 